\title{
Impact of Interest Rate Risk on Supply Chain Network under Bank Credit and Trade Credit Financing
}

\author{
Jie Zhang $\mathbb{D}^{1}{ }^{1}$ Zhiying Zhang $(\mathbb{D})^{2}$ and Yuehui Liu ${ }^{1}{ }^{1}$ \\ ${ }^{1}$ School of Economics and Management, North China Institute of Aerospace Engineering, Langfang 065000, China \\ ${ }^{2}$ School of Economics and Management, Hebei University of Technology, Tianjin 300401, China \\ Correspondence should be addressed to Zhiying Zhang; zzying76@126.com
}

Received 20 May 2021; Revised 17 September 2021; Accepted 9 November 2021; Published 8 December 2021

Academic Editor: Miladin Stefanović

Copyright (c) 2021 Jie Zhang et al. This is an open access article distributed under the Creative Commons Attribution License, which permits unrestricted use, distribution, and reproduction in any medium, provided the original work is properly cited.

The purpose of this study is to propose a methodology that reflects the impact of interest rate risk on firms in supply chain network under bank financing and trade credit and further describe how trade credit improves the impact of interest rate risk on supply chain network through a financial flow equilibrium. A mean-variance framework and a network equilibrium analysis are integrated to provide a modeling framework. The model allows for the investigation of how bank credit financing (BCF) and trade credit financing (TCF) affect the payment strategy and financial flow of interconnected firms in supply chain networks and how they are affected by interest rate risks. The optimal behavior of manufacturers and retailers is described through variational inequality. We construct a supply chain network equilibrium model and derive qualitative properties of the solution and the function that becomes assimilated to the variational inequality problem. Additionally, variational inequality is solved using the modified projection method. This study extends the research on the impact of interest rate risk on the decision in supply chain network of firms. While other studies focus on the game between banks and firms, only a few authors have made attempts to examine the game between one manufacturer and one retailer in supply chain. An effective trade credit strategy is obtained by balancing cash and credit transactions. Through the case study, we learn how to balance the capital flow effectively to improve the negative impact of interest rate risk on supply chain.

\section{Introduction}

The complex global network of supply chain is gradually emerging. The complex network systems are vulnerable to various risks. As for the supply chain network, financial risks are becoming increasingly prominent and critical in the current global economy.

Some emerging markets are experiencing big swings in financial markets, following the global economic restructuring and the intensification of trade disputes. In Turkey, for example, since May 2018, the overnight interest rate has doubled in a few months. Consequently, more than 100,000 small businesses went bankrupt in 2018; bankrupt enterprises further increased by more than $10 \%$ of their increase in the previous year. According to the investigation of TESK, cash flow shortage and short-term payment difficulties owing to the increase in the interest rate are the main reasons. Countries as far away as Argentina and Indonesia have not escaped the ripple effects of Turkey's economic woes. Since 2020, the financial volatility has continued to increase in the context of the uncertainty brought about by the COVID-19 pandemic $[1,2]$. Moreover, the firms in the global supply chain will continue to suffer adverse effects [3]. Therefore, it is more critical to analyze the operation strategy of the supply chain network under financial risks.

Studies are increasingly paying attention to the impact of financial risk on firms. Yang and Zhang examined the impact of interest rate marketization on the enterprise financing costs. The results show that the relationship between the cost of enterprise financing and the degree of interest rate marketization is significantly positive. Improving accounting conservatism can alleviate the pressure brought about by the increase in the cost of financing [4]. Dai and Lin investigated the impact of interest rate fluctuations on the inventory investment of manufacturing enterprises. The results showed that enterprises with stronger capital constraints are more exposed to interest rate fluctuations in inventory investment [5]. 
The above background requires us to study financial risk from the perspective of interconnected supply chain. Zhang and Buzacott considered asset-based financing when making production decisions to determine supply chain ordering and interest rate under market uncertainty [6]. Dada and $\mathrm{Hu}$ studied the inventory problem of a capital-constrained newsvendor considering capital constraints, presented a model to determine optimal ordering and interest rate, and conducted further analysis, which showed that the nonlinear loan schedule could coordinate channel benefits effectively [7]. Chen et al. considered financial market competition and a retailer's capital constraints and further analyzed ordering and interest rate decisions. The results show that the interest rate of financial institutions will increase with the financing scale and market investment return. The degree of capital market competition is further expected to influence the decisions of the retailer, supplier, and financial institution, directly [8]. Wen and Ye examined the game between banks and enterprises in TCF and showed that relaxing the floating range of bank interest rate could improve the credit enthusiasm of banks, hence reducing the overall financing cost of enterprises. They further showed that the loan ratio could be used as a risk control tool with interest rate to achieve better performance among both banks and enterprises [9]. $\mathrm{Yu}$ and Zhen used the risk measurement criterion of Conditional Value at Risk (CVaR) as the decision standard, established the bank loan interest rate decision model based on the minimum conditional risk value, and obtained the optimal interest rate under the condition of balancing risks and benefits [10]. Under the background of interest rate liberalization, Yu and Wang constructed a three-party game model of the supply chain comprising the suppliers and retailers that banks are associated with and examined the influence of bank loan interest rate setting on the supply chain and the operation status of node enterprises [11]. Tan and Yang constructed a three-dimension game model involving suppliers, retailers, and banks in the context of interest rate marketization and explored how to achieve optimal strategies for the parties involved in financing business to achieve their respective interests, especially how to conduct risk control and determine the optimal self-loan interest rate. The above research shows that supply chain finance can optimize the financial flow at an interorganizational level to reduce financial costs. Supply chain finance is also an effective approach to managing financial risk [12].

Trade credit is an important and widely used financing channel in the supply chain. This is an allowable delay in payment for goods purchase and is considered as short-term financing for capital-constrained supply chains. A large number of surveys show that about $80 \%$ of companies in the United States and other European countries provide trade credit to customers during product sales [13, 14]. In less developed countries, formal financial institutions are scarce and inefficient, and trade credit plays a more important role [15]. Many studies focus on the use of trade credit in the supply chain. Goyal first proposed an economic order quantity (EOQ) model with a fixed delay payment term [16]. Chen found that, by concentrating distribution financing on manufacturers, trade credit better integrates channels than bank credit [17]. Lee et al. examined how trade credit affects the horizontal and vertical competition of supply chain [18]. Yang and Birge examined the effectiveness of strengthening supply chain membership by allowing retailers to share part of the demand risk in trade credit and further analyzed the impact of trade credit on supply chain performance [19]. Peura et al. provided a new perspective by studying whether trade credit benefits suppliers. They found that the horizontal benefits of trade credit can supplement its vertical role [20]. $\mathrm{Du}$ et al. studied the coordination of a two-level supply chain using trade credit and wholesale price discounts. The analysis showed that such a policy is beneficial to both sides [21]. Zhang et al. examined the supplier's optimal payment mode selection and the retailer's replenishment strategy. The analysis showed that the supplier tends to choose credit payment when the default risk and capital opportunity cost are smaller [22]. Gang et al. discussed the operational mechanism and coordination of supply chain under trade credit. By introducing a buy-back contract, the retailer's financial constraints are alleviated, and the supply chain is coordinated [23]. The above research shows that trade credit is an effective means of coordination, which can enhance the performance of supply chain. The following studies further considered the impact of different factors on the supply chain policy under trade credit. Rana et al. developed an EOQ inventory model for the growing fresh products; the retailer is offered the trade credit and clears the payment after completing the replenishment cycle [24]. Pal et al. investigated the inventory model considering quality improvement efforts and promotion efforts under the two-tier credit policy [25].

Previous studies have focused on the trade credit decision-making of one or two firms in the supply chain. Our research differs from the aforementioned studies in that we focus on the direct impact of interest rate risk on financial flow among firms. Our study is significant in the following ways: (1) We adopt an innovative method, which integrates the theory of finance into the equilibrium modeling of supply chain network and further integrates interest rate risk into the business relationships between firms in supply chain network. (2) We consider trade credit between competing manufacturers and retailers; the research conclusion differs from the previous model of single manufacturer and single retailer. (3) The model allows for the investigation of how BCF and TCF affect the payment strategy and financial flow of interconnected firms in supply chain networks and how they are affected by interest rate risks. Particularly, we use numerical examples to analyze the following problems:

(1) In BCF and TCF, how does interest rate uncertainty affect payment strategy, ordering strategy, and the profit of firms with different risk appetite?

(2) Compared with BCF, can TCF alleviate the negative impact of interest rate risk on the profit of supply chain network?

This paper proceeds as follows: in Sections 2 and 3, we develop the BCF and TCF supply chain network equilibrium model under interest rate risk. We construct a variational 
inequality model that takes into account the interest rate risk appetite of the decision-makers, along with the equilibrium conditions. We propose qualitative properties of the model and provide a computational procedure. In Section 4, we present a series of computational examples to examine the impacts of interest risk on the profits and decisions of supply chain firms under BCF and TCF. Our results suggest that, compared with BCF, TCF can mitigate the profit reduction of supply chain network brought by interest rate risk. Section 5 concludes the study and highlights the managerial insights.

\section{BCF Supply Chain Network Equilibrium Model}

In this section, we develop the supply chain network equilibrium model under BCF. Our model comprises two tiers of decision-makers, namely, I manufacturers and $\mathrm{J}$ retailers. In the model, a typical manufacturer is denoted by $i$ and a typical retailer is denoted by $j$. In the BCF supply chain, retailers pay for products to manufacturers in cash, which is received from BCF. Retailers are expected to pay back the loan upon completing the marketing sales and when profit is realized. Retailers' financing cost of bank loans is affected by the uncertainty of interest rates in financial markets.

There is cash payment flow only in the BCF supply chain network. The supply chain network structure is as depicted in Figure 1. The solid links in Figure 1 represent product flows. The dotted links represent the financial flow. The cash payment flow is given in the following.

We discuss the behaviors of the manufacturers and retailers in the $\mathrm{BCF}$ supply chain and then provide the variational inequality formulation governing the BCF supply chain network equilibrium. In the following model, we denoted the equilibrium solution by "**" Unless otherwise noted, all vectors are assumed to be column vectors.

\subsection{Manufactures' Optimality Conditions under BCF.} Under BCF, the manufacturers produce their products and sell products to the retailers through cash payments. Let $q_{i j 1}$ be the amount of product flow between manufacturer $i$ and retailer $j$. Group the amount of product flow of all the manufacturers into the $i j$-dimensional column vector $Q_{1}$. Let $p_{i j 1}$ be the product price charged by manufacturer $i$ to retailer $j$. Next, we will discuss how this price is arrived at in equilibrium. The prices of the manufacturers are grouped into the $i j$-dimensional column vector $P_{1}$. Manufacturer $i$ ' unit production cost is denoted by $c_{m i}$, and overhead cost is denoted by $C_{m i}$. Manufacturer $i$ 's production capacity is denoted by $P C_{i}$.

Manufacturer $i$ 's total costs are equal to the sum of the production cost plus the overhead cost. Consequently, the revenue is equal to the price charged by the manufacturer for the product (the retailers are willing to pay) times the total quantity of products purchased by all the retailers from the manufacturer.

We assume that each manufacturer maximizes the total profit. The optimization problem faced by manufacturer $i$ can be expressed as follows:

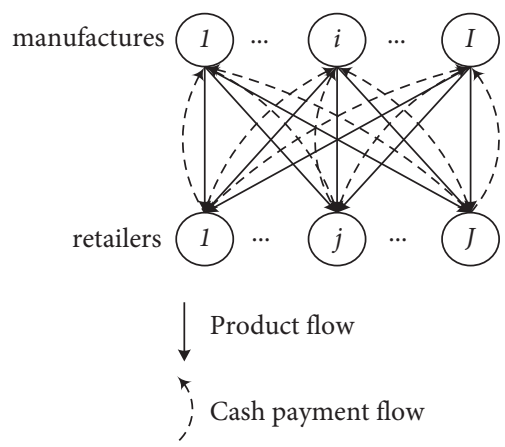

FIgURE 1: Structure of BCF supply chain network.

$$
\begin{gathered}
\operatorname{Max} F_{i}=\sum_{j=1}^{J}\left[P_{i j 1}^{*} q_{i j 1}-c_{m i} q_{i j 1}\right]-C_{m i}, \\
\text { s.t. } \sum_{j=1}^{J} q_{i j 1} \leq P C_{i}, \\
q_{i j 1} \geq 0, \quad \forall j .
\end{gathered}
$$

The first term in the objective function $\sum_{j=1}^{J} p_{i j 1}^{*} q_{i j 1}$ represents the revenue from all the retails and the cash payment flow from the retailers. The second term represents the production cost. Constraint equation (3) states that the total products supplies to all the retailers cannot exceed manufacturer $i$ 's capacity $P C_{i}$.

Let $\lambda_{i}$ be the Lagrangian multiplier of constraint equation (2) and group all $\lambda_{i}$ into vector $\lambda$. We assume that the manufacturers compete in a noncooperative manner and the cost functions are convex. The optimality conditions of all the suppliers can be represented using the following variational inequality: determine $\left(Q_{1}^{*}, \lambda^{*}\right) \in R_{+}^{I+I}$ satisfying

$$
\begin{aligned}
& \sum_{i=1}^{I} \sum_{j=1}^{J}\left[c_{m i}-p_{i j 1}^{*}+\lambda_{i}^{*}\right] \times\left[q_{i j 1}-q_{i j 1}^{*}\right] \\
& \quad+\sum_{i=1}^{I}\left[P C_{i}-\sum_{j=1}^{J} q_{i j 1}^{*}\right] \times\left[\lambda_{i}-\lambda_{i}^{*}\right] \geq 0 \\
& \quad \forall\left(Q_{1}, \lambda\right) \in R_{+}^{I J+I} .
\end{aligned}
$$

2.2. Retailers' Optimality Conditions under BCF. In the BCF supply chain network, retailers purchase products from manufacturers and sell the products to demand markets. Retailers pay for products in cash, which is received from BCF. Retailers further pay back the loan upon completing the marketing sales and when profit is realized. The retailers' financing cost of bank loans is affected by the uncertainty of interest rate in financial markets. Retailers have different risk appetite.

The product flow between retailer $j$ and demand market $k$ is denoted by $q_{j k}$. Group the amount of the product flow of all the retailers into the $j k$-dimensional column vector $Q_{3}$. Each retailer $j$ is faced with a unit handling cost denoted by $c_{r j}$. Each retailer $j$ 's overhead cost is denoted by $C_{r j}$. Retailer $j$ 's degree of risk aversion is denoted by $e_{j}$. 
Retailers procure products and sell to the demand markets. A retailer considers not only the profit but also the interest rate risk. The retailer's interest rate risk is represented by the variance of financing cost. Each retailer maximizes the total profit and minimizes the interest rate risk. Retailer $j$ 's optimization problem can be expressed as follows:

$$
\begin{gathered}
\operatorname{Max} F_{j}=\sum_{k=1}^{K} \rho_{k}\left(\sum_{j=1}^{J} q_{j k}\right) q_{j k}-c_{r j} \sum_{k=1}^{K} q_{j k}-\sum_{i=1}^{I} p_{i j 1}^{*} q_{i j 1}-C_{r j} \\
-\sum_{i=1}^{I} H_{i j 1}\left(r, q_{i j 1}, \pi_{r j}\right)-e_{j} \sum_{i=1}^{I} \sigma_{i j 1}\left(r, q_{i j 1}, \pi_{r j}\right), \\
\text { s.t. } \sum_{k=1}^{K} q_{j k} \leq \sum_{j=1}^{J} q_{i j 1}, \\
q_{j k} \geq 0, q_{i j 1} \geq 0, \forall k, i .
\end{gathered}
$$

The first term $\sum_{k=1}^{K} \rho_{k}\left(\sum_{j=1}^{J} q_{j k}\right) q_{j k}$ represents the revenue from all the markets; $\rho_{k}\left(\sum_{j=1}^{J} q_{j k}\right)$ is the inverse demand function. The second term represents retailer $j$ 's handling cost. The third term is the payout to the manufacturers in cash. The fourth term represents the overhead cost. The fifth term $\sum_{i=1}^{I} H_{i j 1}\left(r, q_{i j 1}, \pi_{r j}\right)$ represents the retailer's expected financing cost. Note that the financial costs depend on the expected interest rate $r$, the retailer's financial situation $\pi_{r j}$, and the amount of product flow between the manufacturer and retailer $q_{i j 1}$. The sixth term $e_{j} \sum_{i=1}^{I} \sigma_{i j 1}\left(r, q_{i j 1}, \pi_{r j}\right)$ represents the variance of the retailer's financing cost. Note that $e_{j}$ reflects the risk-aversion level of the firm. If $e_{j}$ is equal to zero, then retailer $j$ is riskneutral. Constraint equation (6) states that retailer $j$ 's total product supplies to all markets cannot exceed the transaction products made among all the manufacturers.

Let $\mu_{j}$ be the Lagrangian multiplier of constraint equation (6). Group all $\mu_{j}$ into vector $\mu$. We assume that the retailers compete with one another in a noncooperative manner. We further assume that the cost functions for each retailer are continuous and convex. The optimality conditions of all the retailers can be expressed as follows: determine $\left(Q_{1}^{*}, Q_{3}^{*}, \mu^{*}\right) \in R_{*}^{I J+J K+J}$ satisfying

$$
\begin{aligned}
& \sum_{i=1}^{I} \sum_{j=1}^{J}\left[p_{i j 1}^{*}+\frac{\partial H_{i j 1}\left(r, q_{i j 1}^{*}, \pi_{r j}\right)}{\partial q_{i j 1}}+e_{j} \frac{\partial \sigma_{i j 1}\left(r, q_{i j 1}^{*}, \pi_{r j}\right)}{\partial q_{i j 1}}-\mu_{j}^{*}\right] \times\left[q_{i j 1}-q_{i j 1}^{*}\right] \\
& \quad+\sum_{j=1}^{J} \sum_{k=1}^{K}\left[c_{r j}-\rho_{k}\left(\sum_{j=1}^{J} q_{j k}^{*}\right)-\frac{\partial \rho_{k}\left(\sum_{j=1}^{J} q_{j k}^{*}\right)}{\partial q_{j k}} q_{j k}^{*}+\mu_{j}^{*}\right] \times\left[q_{j k}-q_{j k}^{*}\right] \\
& \quad+\sum_{j=1}^{J}\left[\sum_{i=1}^{I} q_{i j 1}^{*}-\sum_{k=1}^{K} q_{j k}^{*}\right] \times\left[\mu_{j}-\mu_{j}^{*}\right] \geq 0 . \\
& \quad \forall\left(Q_{1}, Q_{3}, \mu\right) \in R_{+}^{I+J K+J} .
\end{aligned}
$$

2.3. Equilibrium Conditions of BCF Supply Chain Network. In BCF supply chain network equilibrium, all manufacturers and retailers must meet the optimality conditions at the same time. In addition, manufacturers and retailers must agree on the number of product transactions.

Definition 1. The solution of BCF supply chain network equilibrium needs to meet the sum of equations (4) and (8).
At this time, all manufacturers and suppliers will not change their decisions.

Theorem 1. The conditions required for the BCF supply chain network model to reach the equilibrium state are equivalent to the solution of the following variational inequality problem: determine $\left(Q_{1}^{*}, Q_{3}^{*}, \lambda^{*}, \mu^{*}\right) \in R_{*}^{I J+J K+I+J}$ satisfying

$$
\begin{aligned}
\sum_{i=1}^{I} & \sum_{j=1}^{J}\left[c_{m i}+\lambda_{i}^{*}+\frac{\partial H_{i j 1}\left(r, q_{i j 1}^{*}, \pi_{r j}\right)}{\partial q_{i j 1}}+e_{j} \frac{\partial \sigma_{i j 1}\left(r, q_{i j 1}^{*}, \pi_{r j}\right)}{\partial q_{i j 1}}-\mu_{j}^{*}\right] \times\left[q_{i j 1}-q_{i j 1}^{*}\right] \\
+ & \sum_{j=1}^{J} \sum_{k=1}^{K}\left[c_{r j}-\rho_{k}\left(\sum_{j=1}^{J} q_{j k}^{*}\right)-\frac{\partial \rho_{k}\left(\sum_{j=1}^{J} q_{j k}^{*}\right)}{\partial q_{j k}} q_{j k}^{*}+\mu_{j}^{*}\right] \times\left[q_{j k}-q_{j k}^{*}\right] \\
+ & \sum_{i=1}^{I}\left[P C_{i}-\sum_{j=1}^{J} q_{i j 1}^{*}\right] \times\left[\lambda_{i}-\lambda_{i}^{*}\right]+\sum_{j=1}^{J}\left[\sum_{i=1}^{I} q_{i j 1}^{*}-\sum_{k=1}^{K} q_{j k}^{*}\right] \\
& \times\left[\mu_{j}-\mu_{j}^{*}\right] \geq 0 \\
& \forall\left(Q_{1}, Q_{3}, \lambda, \mu\right) \in R_{+}^{I J+J K+I+J} .
\end{aligned}
$$


Proof. We add equations (4) and (8) to obtain the variational inequality equation (9). Then, the solution of variational inequality equation (9) satisfies the sum of variational inequalities equations (4) and (8). For the convenience of discussion, we express the variational inequality equation (9) as the following standard form:

$$
\left\langle F\left(X^{*}\right)^{T}, X-X^{*}\right\rangle \geq 0, \quad \forall X \in K \equiv R_{+}^{I J+J K+I+J},
$$

where $\quad X \equiv\left(Q_{1}^{*}, Q_{3}^{*}, \lambda^{*}, \mu^{*}\right) \quad$ and $\quad F(X) \equiv$ $\left(F_{i j}, F_{j}\right)_{i=1, \ldots, I ; j=1, \ldots, J}$.

\section{TCF Supply Chain Network Equilibrium Model}

In this section, we develop the TCF supply chain network equilibrium model. The structure of the model is similar to Figure 1. In the TCF supply chain network, retailers pay for products partly in cash payment and partly in credit payment. The retailers' cash is also obtained from BCF. Moreover, the retailers bear the BCF cost. The form of trade credit payments is a delay in payments. The manufacturer delivers the products to the retailer in advance and delays the payments after the retailer completes the sale. The manufacturers further bear the TCF cost. Retailers' BCF costs and manufactures' TCF costs are affected by the interest rate uncertainty. Retailers pay for products using cash and trade credit. Hence, there are cash payment and credit payment flows between manufacturers and retailers. The TCF supply chain network structure is as depicted in Figure 2. The solid links represent product flows. The dotted links represent financial flows which are cash payment and credit payment flows.

We further discuss the behaviors of the manufacturers and the retailers in the TCF supply chain and provide the variational inequality formulation to describe the equilibrium of the TCF supply chain network.

3.1. Manufactures' Optimality Conditions under TCF. In a TCF supply chain network, the manufacturers sell products to the retailers using the mix of credit payment and cash payment.

Let $q_{i j 2}$ be the amount of product flow between manufacturer $i$ and retailer $j$ through TCF. Group the amount of product flow of all the manufacturers into the $i j$-dimensional column vector $Q_{2}$. Let $p_{i j 2}$ be the price charged for the product by manufacturer $i$ to retailer $j$ through TCF. The prices of the manufacturers are grouped into the $i j$-dimensional column vector $P_{2}$. Other symbols and variables are similar to the representation in the BCF supply chain network.

Manufacturer $i$ 's total costs are equal to the sum of their production cost plus the overhead cost and TCF cost. A manufacturer's total revenue is equal to the sum of the cash and the credit payment revenues. Additionally, the manufacturer considers interest rate risk using a mean-variance framework. Each manufacturer maximizes the total profit and minimizes the interest rate risk. The optimization problem faced by manufacturer $i$ can be expressed as follows:

$$
\begin{aligned}
& \operatorname{Max} \sum_{j=1}^{J}\left[p_{i j 1}^{*} q_{i j 1}+p_{i j 2}^{*} q_{i j 2}-c_{m i}\left(q_{i j 1}+q_{i j 2}\right)\right]-C_{m i} \\
&-\sum_{j=1}^{J} H_{i j 2}\left(r, q_{i j 2}, \pi_{m i}\right)-e_{i} \sum_{j=1}^{J} \sigma_{i j 2}\left(r, q_{i j 2}, \pi_{m i}\right), \\
& \text { s.t. } \sum_{j=1}^{J}\left(q_{i j 1}+q_{i j 2}\right) \leq P C_{i}, \\
& q_{i j 1} \geq 0, q_{i j 2} \geq 0, \forall j .
\end{aligned}
$$

The first and the second terms represent the cash payment and credit payment revenues from the retailers. The third, fourth, and fifth terms represent the production, overhead, and credit financial costs, respectively; the last term is the variance of the manufacturer's credit financial cost. Note that the credit financial costs depend on the expected interest rate $r$, manufacturer's financial situation $\pi_{m i}$, and the amount of product flow through credit payment $q_{i j 2} . e_{i}$ in the objective function reflects the risk-aversion level of the manufacturer. Constraint equation (12) states that the total supplies to the retailers cannot exceed manufacturer $i$ 's capacity.

Let $\lambda_{i}$ be the Lagrangian multiplier of constraint equation (12). Group all into vector $\lambda$. We assume that the cost functions are convex, and the manufacturers compete in a noncooperative manner. We further assume that the cost functions for each manufacturer are continuous and convex. The optimality conditions of all retailers can be represented using the following variational inequality: determine $\left(Q_{1}^{*}, Q_{2}^{*}, \lambda^{*}\right) \in R_{+}^{2 I J+I}$ satisfying

$$
\begin{aligned}
& \sum_{i=1}^{I} \sum_{j=1}^{J}\left[c_{m i}-p_{i j 1}^{*}+\lambda_{i}^{*}\right] \times\left[q_{i j 1}-q_{i j 2}\right] \\
& \quad+\sum_{i=1}^{I} \sum_{j=1}^{J}\left[\frac{\partial H_{i j 2}\left(r, q_{i j 2}^{*}, \pi_{m i}\right)}{\partial q_{i j 2}}+e_{i} \frac{\partial \sigma_{i j 2}\left(r, q_{i j 2}^{*}, \pi_{m i}\right)}{\partial q_{i j 2}}+c_{m i}-p_{i j 2}^{*}+\lambda_{i}^{*}\right] \times\left[q_{i j 2}-q_{i j 2}^{*}\right] \\
& +\sum_{i=1}^{I}\left[P C_{i}-\sum_{j=1}^{J}\left(q_{i j 1}^{*}+q_{i j 2}^{*}\right)\right] \times\left[\lambda_{i}-\lambda_{i}^{*}\right] \geq 0 \\
& \quad \forall\left(Q_{1}, Q_{2}, \lambda\right) \in R_{+}^{2 I J+I} .
\end{aligned}
$$




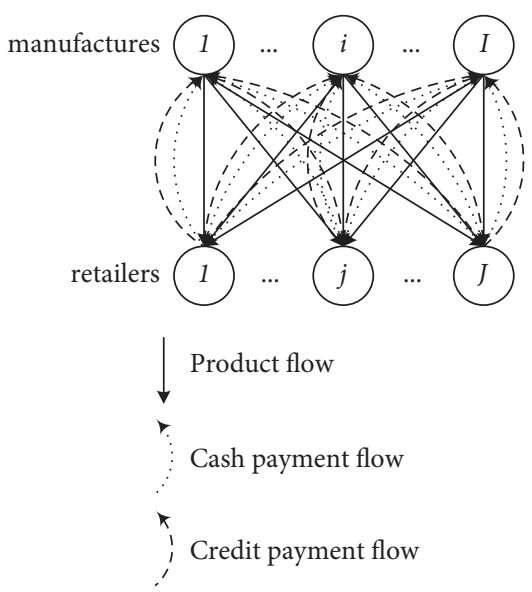

FIGURE 2: Structure of TCF supply chain network.

3.2. Retailers' Optimality Conditions under TCF. In a TCF supply chain network, the retailers purchase products from the manufacturers and sell them to the demand markets. Retailers pay for products partly in cash payment and partly in credit payment. Retailers pay back the bank and trade credit loans upon completing the marketing sales and when profit is realized. The retailers' financing cost of bank loans is affected by the uncertainty of interest rate in financial markets. Retailers have different risk appetite.

Retailers procure products and sell them to the demand markets. The retailer considers not only the profit but also the interest rate risk. The retailer's interest rate risk is represented by the variance of financing cost. Each retailer maximizes the total profit and minimizes the interest rate risk. The optimization problem faced by retailer $j$ can be expressed as follows: the symbols and variables are similar to the representation in the BCF supply chain network.

$$
\begin{gathered}
\operatorname{Max} \sum_{k=1}^{K} \rho_{k}\left(\sum_{j=1}^{J} q_{j k}\right) q_{j k}-c_{r j} \sum_{k=1}^{K} q_{j k}-\sum_{i=1}^{I}\left[p_{i j 1}^{*} q_{i j 1}+p_{i j 2}^{*} q_{i j 2}\right] \\
-C_{r j}-\sum_{i=1}^{I} H_{i j 1}\left(r, q_{i j 1}, \pi_{r j}\right)-e_{j} \sum_{i=1}^{I} \sigma_{i j 1}\left(r, q_{i j 1}, \pi_{r j}\right),
\end{gathered}
$$

$$
\begin{aligned}
& \text { s.t. } \sum_{k=1}^{K} q_{j k} \leq \sum_{j=1}^{J}\left(q_{i j 1}+q_{i j 2}\right), \\
& q_{j k} \geq 0, q_{i j q} \geq 0, q_{i j 2} \geq 0, \forall k, i .
\end{aligned}
$$

The first term $\sum_{k=1}^{K} \rho_{k}\left(\sum_{j=1}^{J} q_{j k}\right) q_{j k}$ represents the revenue from all the markets. The second term represents retailer $j$ 's handling cos; the third and the fourth terms represent the payout to the manufacturers in cash and in trade credit. The fifth term represents the overhead cost. The sixth term represents the retailer's expected financing cost. The seventh term represents the variance of the retailer's financing cost. $e_{j}$ reflects the risk-aversion level of the retailer. All the vectors in this study are considered column vectors unless otherwise. Constraint equation (16) states that retailer $j$ 's total products supply to all markets cannot exceed the transaction products made among all the manufacturers.

Let $\mu_{j}$ be the Lagrangian multiplier of constraint equation (16). Group all $\mu_{j}$ into vector $\mu$. The retailers compete in a noncooperative manner, consistent with Nash. We further assume that the cost functions for each retailer are continuous and convex. The optimality conditions of all the retailers can be represented using the following variational inequality: determine $\left(Q_{1}^{*}, Q_{2}^{*}, Q_{3}^{*}, \mu^{*}\right) \in R_{+}^{2 I J+J K+J}$ satisfying

$$
\begin{aligned}
\sum_{i=1}^{I} & \sum_{j=1}^{J}\left[p_{i j 1}^{*}+\frac{\partial H_{i j 1}\left(r, q_{i j 1}, \pi_{r j}\right)}{\partial q_{i j 1}}+e_{j} \frac{\partial \sigma_{i j 1}\left(r, q_{i j 1}, \pi_{r j}\right)}{\partial q_{i j 1}}-\mu_{j}^{*}\right] \times\left[q_{i j 1}-q_{i j 1}^{*}\right] \\
& +\sum_{i=1}^{I} \sum_{j=1}^{J}\left[p_{i j 2}^{*}-\mu_{j}^{*}\right] \times\left[q_{i j 2}-q_{i j 2}^{*}\right] \\
& +\sum_{i=1}^{I} \sum_{k=1}^{K}\left[c_{r j}-\rho_{k}\left(\sum_{j=1}^{J} q_{j k}^{*}\right)-\frac{\partial \rho_{k}\left(\sum_{j=1}^{J} q_{j k}^{*}\right)}{\partial q_{j k}} q_{j k}^{*}+\mu_{j}^{*}\right] \times\left[q_{j k}-q_{j k}^{*}\right] \\
& +\sum_{j=1}^{J}\left[\sum_{i=1}^{I}\left(q_{i j 1}^{*}+q_{i j 2}^{*}\right)-\sum_{k=1}^{K} q_{j k}^{*}\right] \times\left[\mu_{j}-\mu_{j}^{*}\right] \geq 0 \\
& \forall\left(Q_{1}, Q_{2}, Q_{3}, \mu\right) \in R_{+}^{2 I J+J K+J} .
\end{aligned}
$$


3.3. Equilibrium Conditions of TCF Supply Chain Network. In TCF supply chain network equilibrium, all manufacturers and retailers must meet the optimality conditions at the same time. In addition, manufacturers and retailers must agree on the number of product transactions.

Definition 2. The solution of TCF supply chain network equilibrium needs to meet the sum of equations (14) and
(18). At this time, all manufacturers and suppliers will not change their decisions.

Theorem 2. The conditions required for the TCF supply chain network model to reach the equilibrium state are equivalent to the solution of the following variational inequality problem: determine $\left(Q_{1}^{*}, Q_{2}^{*}, Q_{3}^{*}, \lambda^{*}, \mu^{*}\right) \in$ $R_{+}^{2 I J+J K+I+J}$ satisfying

$$
\begin{aligned}
& \sum_{i=1}^{I} \sum_{j=1}^{J}\left[c_{m i}+\lambda_{i}^{*}+\frac{\partial H_{i j 1}\left(r, q_{i j 1}, \pi_{r j}\right)}{\partial q_{i j 1}}+e_{j} \frac{\partial \sigma_{i j 1}\left(r, q_{i j 1}, \pi_{r j}\right)}{\partial q_{i j 1}}-\mu_{j}^{*}\right] \times\left[q_{i j 1}-q_{i j 1}^{*}\right] \\
& +\sum_{i=1}^{I} \sum_{j=1}^{J}\left[\frac{\partial H_{i j 2}\left(r, q_{i j 2}, \pi_{m i}\right)}{\partial q_{i j 2}}+e_{i} \frac{\partial \sigma_{i j 2}\left(r, q_{i j 2}, \pi_{m i}\right)}{\partial q_{i j 2}}+c_{m i}+\lambda_{i}^{*}-\mu_{j}^{*}\right] \times\left[q_{i j 2}-q_{i j 2}^{*}\right] \\
& +\sum_{j=1}^{J} \sum_{k=1}^{K}\left[c_{r i}-\rho_{k}\left(\sum_{j=1}^{J} q_{j k}^{*}\right)-\frac{\partial \rho_{k}\left(\sum_{j=1}^{J} q_{j k}^{*}\right)}{\partial q_{j k}} q_{j k}^{*}+\mu_{j}^{*}\right] \times\left[q_{j k}-q_{j k}^{*}\right] \\
& +\sum_{i=1}^{I}\left[P C_{i}-\sum_{j=1}^{J}\left(q_{i j 1}^{*}+q_{i j 2}^{*}\right)\right] \times\left[\lambda_{i}-\lambda_{i}^{*}\right] \\
& +\sum_{j=1}^{J}\left[\sum_{i=1}^{I}\left(q_{i j 1}^{*}+q_{i j 2}^{*}\right)-\sum_{k=1}^{K} q_{j k}^{*}\right] \times\left[\mu_{j}-\mu_{j}^{*}\right] \geq 0 \\
& \quad \forall\left(Q_{1}, Q_{2}, Q_{3}, \lambda, \mu\right) \in R_{+}^{2 I J+J K+I+J} .
\end{aligned}
$$

The proof of Theorem 2 can refer to Section 2.3.

\section{Properties of Solution and Solution Method}

In this section, we analyze the properties of the solution and give the solution method of the variational inequality.

4.1. Properties of Solution. If there exists a solution to variational inequality equations (9) or (19), the proof process is similar to Nagurney and Dhanda [26].

Theorem 3. It is assumed that all cost functions in the model are continuously differentiable convex functions. Then, as shown in equation (20), the vector $F$ assimilated into variational inequality equation (20) is monotonic; that is,

$$
\left\langle\left(F\left(X^{\prime}\right)-F\left(X^{\prime \prime}\right)\right)^{T}, X^{\prime}-X^{\prime \prime}\right\rangle \geq 0, \quad \forall X^{\prime}, X^{\prime \prime} \in \kappa, X^{\prime} \neq X^{\prime \prime} .
$$

Proof. If all cost functions in the model are continuously differentiable convex functions, the vector $F$ assimilated into the variational inequality is convex. So, vector $F$ is monotonic.
4.2. Modified Projection Method. We apply the modified projection method to solve variational inequality equation (9); the steps are as follows:

\section{Step 0. Initialization}

Set $X_{0}=\left(Q_{10}, Q_{30}, \lambda_{0}, \mu_{0}\right) \in \kappa$ and $T=10<\alpha \leq(1 / L)$, where $L$ is the Lipschitz continuity constant.

Step 1. Computation

The solution $\bar{X}_{T}$ is obtained by solving the following variational inequality:

$$
\left\langle\bar{X}_{T}+\alpha F\left(X_{T-1}\right)-X_{T-1}, X-\bar{X}_{T}\right\rangle \geq 0, \quad \forall X \in \kappa .
$$

\section{Step 2. Adaptation}

The solution $X_{T}$ is obtained by solving the following variational inequality:

$$
\left\langle X_{T}+\alpha F\left(\bar{X}_{T}\right)-X_{T-1}, X-X_{T}\right\rangle \geq 0, \quad \forall X \in \kappa .
$$

Step 3. Convergence verification

If $\max \left|X_{T}-X_{T-1}\right| \leq \varepsilon$, with $\varepsilon>0$, a prespecified tolerance, then stop; otherwise, set $T=T+1$, and proceed to Step 1 . We set the parameter $\alpha=0.05$ and the tolerance $\varepsilon=0.00001$. 
The variational inequality equation (19) is solved using the same method.

\section{Computational Study}

In this section, we examine the impacts of interest rate uncertainty on the decision-making of firms with different risk appetite in the BCF and TCF supply chain network. Particularly, we use a computational example to answer the questions raised in the introduction section.

In the simple and focused example we give, the supply chain comprises two manufacturers and two retailers. As this study focuses on the impacts of interest rate on the decision-making of supply chain firms with different risk appetite, we assume that retailer $j=1$ is risk-neutral and retailer $j=2$ is risk-averse: $e_{j=1}=0$ and $e_{j=2}=0.25$. The two manufacturers are risk-averse: $e_{i=1}=0.25$ and $e_{i=2}=0.25$. In addition, where we assume that both the manufacturers and retailers have the same cost and production parameters. The parameters are

$$
\begin{aligned}
c_{m i} & =2, \quad i=1,2, \\
C_{m i} & =10, \quad i=1,2, \\
c_{r j} & =2, \quad j=1,2, \\
C_{r j} & =50, \quad j=1,2, \\
H_{i j 1}\left(r, q_{i j 1}, \pi_{r j}\right) & =5 r \pi_{r j}\left(q_{i j 1}\right)^{2}, \quad i=1,2, j=1,2, \\
H_{i j 2}\left(r, q_{i j 2}, \pi_{m i}\right) & =5 r \pi_{m i}\left(q_{i j 2}\right)^{2}, \quad i=1,2, j=1,2, \\
\pi_{r 1} & =0.25, \pi_{r 2}=0.5, \pi_{m i}=0.25, \quad i=1,2, \\
P C_{i} & =12, i=1,2, \\
\rho_{k}\left(\sum_{j=1}^{J} q_{j k}\right) q_{j k} & =30-0.5\left(q_{1 k}+q_{2 k}\right), \quad k=1 .
\end{aligned}
$$

Based on the interest rate volatilities in several normal and crisis periods, we assume that the interest rate variance $\sigma^{2}$ varies from 0 to 0.1 (step length is 0.01 ), which represents the interest rate risk change from low to high.

\subsection{Impact of Interest Rate Risk on BCF Supply Chain} Network. Tables 1-4 show how interest rate uncertainty affects payment strategies, ordering strategies, and profit of firms with different risk appetite in a BCF supply chain.

When interest rate uncertainty increases, all the cash financial flow decreases. As the cash flow payment for products is received from $\mathrm{BCF}$, both retailers' $\mathrm{BCF}$ scale decreases gradually; retailer 2's BCF scale decreases more significantly. Retailer 2's profit decline and retailer 1's profit increase with the increase of interest rate uncertainty. This is because when the interest rate is higher, the market sales of the risk-averse retailer 2 decrease; as the competition between retailers, the risk-neutral retailer 1's market sales increases. Therefore, in a BCF supply chain, a risk-neutral retailer can occupy a bigger part of the market with stable cash flow and therefore make higher profits and achieve more market competitiveness.
Moreover, the profits of the two manufacturers decline as the lower transaction prices increase.

\subsection{Impact of Interest Rate Risk on TCF Supply Chain} Network. Tables 5-8 show how interest rate uncertainty affects the payment strategy, ordering strategy, and profit of firms with different risk appetite in a TCF supply chain network.

When interest rate uncertainty increases, the credit transaction price of retailer 2 increases, while the credit transaction price of retailer 1 decreases, as manufacturers will provide more price discounts for risk-neutral retailers to obtain more stable financial flows with the increase of interest rate risk.

The gap between the cash transaction price and the credit transaction price increases because manufacturers hope to obtain more cash with the increase of interest rate risk, avoid loss of credit risk through significant discounts on cash transactions, and get more cash payment flows. In this case, the risk-neutral retailer 1 gets more price discounts; further, their product transactions through cash payment increase gradually. Manufacturers offer higher credit transaction prices to retailer 2 than to retailer 1 . The reason is that retailer 2 is risk-averse and is more likely to be affected by interest rate risk, and so retailer 2 has to pay a significant premium to get trade credits. Therefore, their credit transaction price increases gradually and leads to a decrease in retailer 2's product transactions.

$\sum_{i=1}^{2} q_{i 11}^{*} p_{i 11}^{*}$ and $\sum_{i=1}^{2} q_{i 12}^{*} p_{i 12}^{*}$ represent retailer 1 's cash and credit financial flow. $\sum_{i=1}^{2} q_{i 21}^{*} p_{i 21}^{*}$ and $\sum_{i=1}^{2} q_{i 22}^{*} p_{i 22}^{*}$ represent retailer 2 's cash and credit financial flow. As interest rate risk increases, retailer 1's cash financial flow increases, owing to the increase in retailer 1's products flow through cash transactions. Simultaneously, retailer 1's credit financial flow decreases, while retailer 2's cash financial flow and credit financial flow decrease gradually. The retailers' cash financial flow comes from bank loans. Therefore, in a TCF supply chain network, bank credit scale increases, while trade credit scale decreases. When interest rate risk increases, manufacturers offer less TCF to avoid incurring losses.

When interest rate uncertainty increases, the risk-neutral retailer 1's profit increases, while the risk-averse retailer 2's profit decreases. Risk-neutral retailers have a competitive advantage in this case. The profits yielded by the two manufacturers and the total profit of the supply chain network decrease gradually.

5.3. Impact of TCF on the Profit. Figures 3(a) and 3(c) show that, under TCF, the profit of a manufacturer and the total profit of the supply chain network are higher than BCF. The profit growth rates increase with interest rate risk. This is because TCF can reduce the total financial cost and improve the efficiency of capital utilization. TCF can alleviate the decline of total profit caused by interest rate risk. Moreover, the higher the interest rate risk is, the more significant the effect is. 
TABle 1: Product flow through cash in BCF supply chain network.

\begin{tabular}{lccccccccccc}
\hline Product flow & & & & \multicolumn{1}{c}{$\sigma^{2}$} & & & \\
& 0.000 & 0.010 & 0.020 & 0.030 & 0.040 & 0.050 & 0.060 & 0.070 & 0.080 & 0.090 & 0.100 \\
\hline$\sum_{1}^{2} q_{i 11}^{*}$ & 12.000 & 13.827 & 14.749 & 15.360 & 15.812 & 16.169 & 16.462 & 16.710 & 16.923 & 17.110 & 17.277 \\
$\sum_{1}^{2} q_{i 21}^{*}$ & 12.000 & 10.173 & 9.251 & 8.640 & 8.188 & 7.831 & 7.538 & 7.291 & 7.077 & 6.890 & 6.723 \\
\hline
\end{tabular}

Table 2: Price charged by the manufacturers through cash in BCF supply chain network.

\begin{tabular}{|c|c|c|c|c|c|c|c|c|c|c|c|}
\hline \multirow{2}{*}{ Price } & \multicolumn{11}{|c|}{$\sigma^{2}$} \\
\hline & 0.000 & 0.010 & 0.020 & 0.030 & 0.040 & 0.050 & 0.060 & 0.070 & 0.080 & 0.090 & 0.100 \\
\hline$P_{i 11}^{*}(i=1,2)$ & 9.250 & 8.222 & 7.704 & 7.360 & 7.106 & 6.905 & 6.740 & 6.601 & 6.481 & 6.376 & 6.282 \\
\hline$P_{i 21}^{*}(i=1,2)$ & 9.250 & 8.222 & 7.704 & 7.360 & 7.106 & 6.905 & 6.740 & 6.601 & 6.481 & 6.376 & 6.282 \\
\hline
\end{tabular}

TABLE 3: Cash financial flow in BCF supply chain network.

\begin{tabular}{lccccccccccc}
\hline Cash financial flow & \multicolumn{1}{c}{$\sigma^{2}$} \\
& 0.000 & 0.010 & 0.020 & 0.030 & 0.040 & 0.050 & 0.060 & 0.070 & 0.080 & 0.090 & 0.100 \\
\hline$\sum_{i=1}^{2} q_{i 11}^{*} p_{i 11}^{*}$ & 110.999 & 113.689 & 113.623 & 113.049 & 112.356 & 111.647 & 110.957 & 110.298 & 109.675 & 109.086 & 108.530 \\
$\sum_{i=1}^{2} q_{i 21}^{*} p_{i 21}^{*}$ & 110.999 & 83.639 & 71.267 & 63.595 & 58.181 & 54.074 & 50.808 & 48.125 & 45.865 & 43.926 & 42.236 \\
\hline
\end{tabular}

TABLE 4: Firms' profit in BCF supply chain network.

\begin{tabular}{|c|c|c|c|c|c|c|c|c|c|c|c|}
\hline \multirow{2}{*}{ Profit } & \multicolumn{11}{|c|}{$\sigma^{2}$} \\
\hline & 0.000 & 0.010 & 0.020 & 0.030 & 0.040 & 0.050 & 0.060 & 0.070 & 0.080 & 0.090 & 0.100 \\
\hline$F_{i=1,2}^{*}$ & 76.999 & 64.664 & 58.444 & 54.322 & 51.269 & 48.860 & 46.882 & 45.211 & 43.770 & 42.506 & 41.383 \\
\hline$F_{j=1}^{*-1,2}$ & 26.502 & 51.577 & 65.563 & 75.333 & 82.825 & 88.885 & 93.964 & 98.326 & 102.142 & 105.528 & 108.567 \\
\hline$F_{j=2}^{*=1}$ & 26.502 & 25.887 & 24.076 & 22.317 & 20.730 & 19.308 & 18.026 & 16.864 & 15.803 & 14.828 & 13.927 \\
\hline$F^{*}$ & 207.001 & 206.792 & 206.527 & 206.295 & 206.092 & 205.913 & 205.755 & 205.613 & 205.485 & 205.367 & 205.259 \\
\hline
\end{tabular}

TABle 5: Product flow through cash in TCF supply chain network.

\begin{tabular}{lccccccccccc}
\hline Product flow & 0.000 & 0.010 & 0.020 & 0.030 & 0.040 & 0.050 & 0.060 & 0.070 & 0.080 & 0.090 & 0.100 \\
\hline$\sum_{i=1}^{2} q_{i 11}^{*}$ & 6.000 & 7.671 & 8.451 & 9.003 & 9.439 & 9.804 & 10.118 & 10.396 & 10.644 & 10.869 & 11.075 \\
$\sum_{i=1}^{2} q_{i 12}^{*}$ & 6.000 & 4.609 & 4.109 & 3.810 & 3.600 & 3.440 & 3.311 & 3.203 & 3.111 & 3.031 & 2.961 \\
$\sum_{i=1}^{2} q_{i 21}^{*}$ & 6.000 & 5.860 & 5.720 & 5.594 & 5.481 & 5.378 & 5.286 & 5.201 & 5.122 & 5.050 & 4.982 \\
$\sum_{i=1}^{2} q_{i 22}^{*}$ & 6.000 & 5.860 & 5.720 & 5.594 & 5.481 & 5.378 & 5.286 & 5.201 & 5.122 & 5.050 & 4.982 \\
\hline
\end{tabular}

TABLE 6: Price charged by the manufacturers through cash and credit in TCF supply chain network.

\begin{tabular}{lccccccccccc}
\hline Price & & \multicolumn{10}{c}{$\sigma^{2}$} \\
& 0.000 & 0.010 & 0.020 & 0.030 & 0.040 & 0.050 & 0.060 & 0.070 & 0.080 & 0.090 & 0.100 \\
\hline$p_{i 11}^{*}(i=1,2)$ & 9.625 & 9.381 & 9.192 & 9.031 & 8.891 & 8.766 & 8.653 & 8.551 & 8.457 & 8.371 & 8.290 \\
$p_{i 12}^{*}(i=1,2)$ & 10.000 & 9.860 & 9.720 & 9.594 & 9.481 & 9.379 & 9.286 & 9.201 & 9.123 & 9.050 & 8.983 \\
$p_{i 21}^{*}(i=1,2)$ & 9.625 & 9.381 & 9.192 & 9.031 & 8.891 & 8.766 & 8.654 & 8.551 & 8.458 & 8.371 & 8.291 \\
$p_{i 22}^{*}(i=1,2)$ & 10.000 & 10.140 & 10.280 & 10.406 & 10.519 & 10.622 & 10.714 & 10.799 & 10.878 & 10.950 & 11.018 \\
\hline
\end{tabular}

Figure 3(b) shows that retailers' profit under TCF is lower than under BCF. This is because of the competition between retailers and the marginal effect. To balance the trade credit financial cost, the price offered by manufacturers under TCF is higher than that under BCF. Under the complete information and noncooperative competition, retailers can only accept the equilibrium price, which will otherwise yield lower profits. Consequently, the retailers' procurement cost increases, while the total profits decrease. The profit of a riskneutral retailer decreases more significantly than that of a risk-averse retailer. In a TCF supply chain network, the market sales and profit gaps between the two retailers get 
TABLE 7: Cash and credit financial flow in TCF supply chain network.

\begin{tabular}{lccccccccccc}
\hline Cash and credit financial flow & & & & \multicolumn{1}{c}{$\sigma^{2}$} \\
& 0.000 & 0.010 & 0.020 & 0.030 & 0.040 & 0.050 & 0.060 & 0.070 & 0.080 & 0.090 & 0.100 \\
\hline$\sum_{i=1}^{2} q_{i 11}^{2} p_{i 11}^{*}$ & 57.749 & 71.955 & 77.679 & 81.301 & 83.917 & 85.936 & 87.558 & 88.895 & 90.021 & 90.982 & 91.813 \\
$\sum_{i=1}^{2} q_{i 12}^{2} p_{i 12}^{*}$ & 59.999 & 45.449 & 39.942 & 36.556 & 34.132 & 32.259 & 30.740 & 29.469 & 28.381 & 27.432 & 26.594 \\
$\sum_{i=1}^{2} q_{i 21}^{2} p_{i 21}^{*}$ & 57.749 & 54.971 & 52.574 & 50.517 & 48.726 & 47.147 & 45.739 & 44.471 & 43.322 & 42.271 & 41.306 \\
$\sum_{i=1}^{2} q_{i 22}^{2} p_{i 22}^{*}$ & 59.999 & 59.420 & 58.800 & 58.209 & 57.651 & 57.126 & 56.631 & 56.163 & 55.718 & 55.296 & 54.893 \\
\hline
\end{tabular}

TABLe 8: Firms' profit in TCF supply chain network.

\begin{tabular}{lccccccccccc}
\hline Profit & & & & & $\sigma^{2}$ & & & \\
& 0.000 & 0.010 & 0.020 & 0.030 & 0.040 & 0.050 & 0.060 & 0.070 & 0.080 & 0.090 & 0.100 \\
\hline$F_{i=1,2}^{*}$ & 82.624 & 81.029 & 79.723 & 78.575 & 77.542 & 76.597 & 75.726 & 74.917 & 74.160 & 73.449 & 72.779 \\
$F_{j=1}^{*}$ & 23.127 & 27.236 & 31.116 & 34.616 & 37.792 & 40.694 & 43.365 & 45.839 & 48.144 & 50.300 & 52.325 \\
$F_{j=2}^{*}$ & 23.127 & 22.058 & 20.635 & 19.292 & 18.059 & 16.931 & 15.895 & 14.940 & 14.054 & 13.230 & 12.460 \\
$F^{*}$ & 211.501 & 211.352 & 211.196 & 211.058 & 210.934 & 210.819 & 210.712 & 210.612 & 210.517 & 210.428 & 210.342 \\
\hline
\end{tabular}

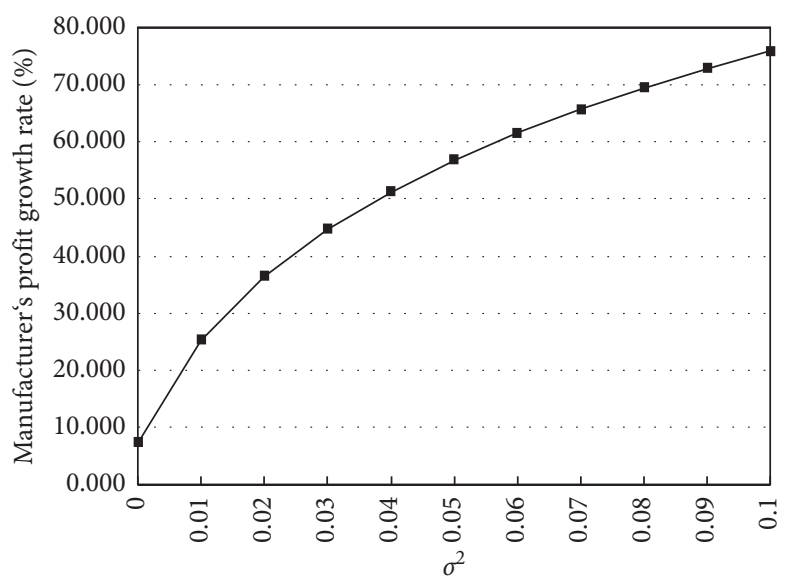

(a)

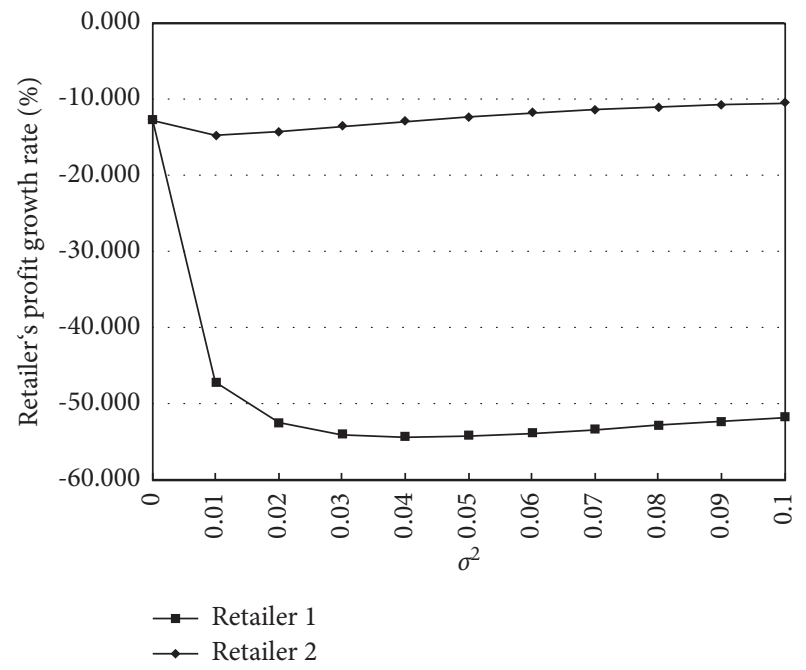

(b)

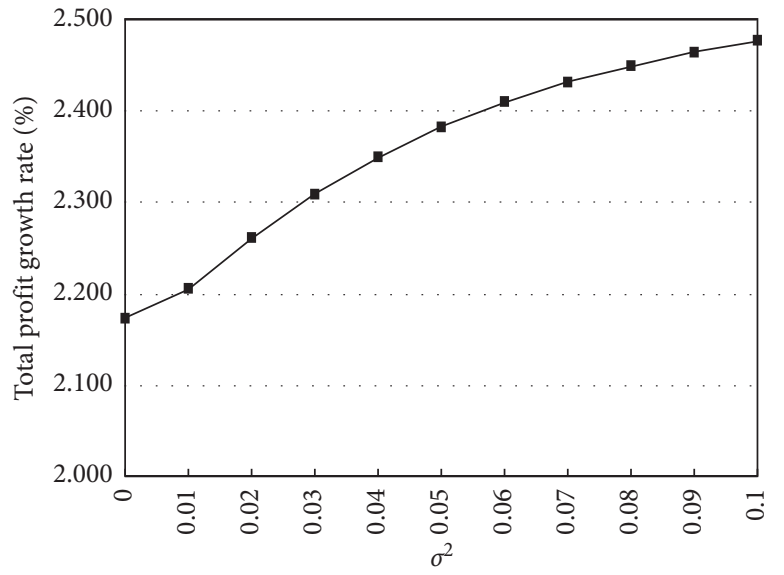

(c)

Figure 3: Impact of TCF on the profit of supply chain network. 
smaller than those in a BCF supply chain network. This shows that, compared with BCF, TCF narrows the competition gap between the two retailers with different risk attitude.

\section{Conclusion}

This study examines the impact of interest rate risk on the decision-making and profit of supply chain firms under BCF and TCF from the perspective of network. In particular, we develop a variational inequality model to solve the equilibrium decision-making problem of heterogeneous supply chain firms with different risk appetite. At the same time, it provides important qualitative property analysis for the model and gives the algorithm of how to get the convergent solution. We further use a series of numerical examples to answer the following questions: what is the change law of financing, profitability, and decisionmaking of supply chain firms under interest rate risk. Compared with BCF, TCF can alleviate the negative impact of interest rate risk in supply chain network and improve the profitability of supply chain network; the higher the interest rate risk is, the more significant it is to improve the profitability. In a TCF supply chain network, the profit growth rate of a risk-averse retailer is higher than that of a risk-neutral retailer. TCF can further narrow the competitive gap between retailers with different risk appetite.

The conclusions of this work provide important management insights for decision-makers to solve the supply chain decision-making problem under the environment of uncertain interest rate:

(1) For manufacturers, TCF plays a very important role in managing the negative impact of interest rate uncertainty. Compared with BCF, TCF can allocate the material and financing more efficiently in a supply chain network to improve the profitability of the supply chain network.

(2) When weighing cash and credit transactions, manufacturers and retailers should consider not only the transactions between the upstream and downstream but also the transaction strategy of the competitors at the same level.

(3) Additionally, manufacturers should provide better terms of credit payment or more price discounts to create more business opportunities to further manage interest rate risk through more stable financial flows. When interest rate risk increases, risk-neutral retailers are likely to have relatively stable financial flows.

(4) Moreover, retailers should optimize their strategies, adjust their risk appetite, and increase the stability of financial flows to obtain more price discounts from manufacturers and gain advantages in the supply chain competition.

The possible expansion direction of this work is to consider the dynamic decision-making of multiple trading cycles. Additionally, future studies should investigate how the long-term transaction relationship between manufacturers and retailers influences supply chain decisions.

\section{Data Availability}

The basic data used to support the findings of this study are included within the supplementary information file.

\section{Additional Points}

This is an open-access article published under a Creative Commons Attribution license. As long as the original works are correctly cited according to the rules, they can be used without restrictions.

\section{Conflicts of Interest}

The authors declare that they have no conflicts of interest.

\section{Acknowledgments}

This research was supported by the Initial Scientific Research Foundation for the Doctor Teachers in the North China Institute of Aerospace Engineering (BKY-2020-07), Hebei Social Science Foundation Project (HB21GL017), Special Project of Soft Science Research in Hebei Province (21557681D), and Soft Science Project of Langfang Science Technology Committee (2021029019).

\section{Supplementary Materials}

The datasets of the computational study in this paper can be seen in the Supplemental File "BASIC DATA-Impact of Interest Rate Risk on Supply Chain Network under Bank Credit and Trade Credit Financing.". (Supplementary Materials)

\section{References}

[1] C. T. Albulescu, "COVID-19 and the United States financial markets' volatility," Finance Research Letters, vol. 38, pp. 1-5, 2021.

[2] C. T. Albulescu, "Coronavirus and financial volatility: 40 days of fasting and fear," HAL Working Paper, no. 02501814, 2020.

[3] W. X. Zhu, P. Zhang, P. F. Li, and Z. Y. Wang, "Firm crisis, government support and policy efficiency under the epidemic shock: evidence from two waves of questionnaire on SMEs," Management World, vol. 4, pp. 13-26, 2020.

[4] C. H. Yang and K. L. Zhang, "The debt financing cost of private listed firms-based on rate marketization and accounting conservation," Chinese Journal of Management Science, vol. 24, no. 11, pp. 405-412, 2016.

[5] Y. K. Dai and S. Lin, "Interest rate volatility, financial constraints, and inventory investment: evidence from Chinese manufactural firms," Journal of Financial Research, vol. 442, no. 4, pp. 95-111, 2017.

[6] R. Q. Zhang and J. Buzacott, "Inventory management with asset-based financing," Management Science, vol. 50, no. 9, pp. 1274-1292, 2004.

[7] M. Dada and Q. Hu, "Financing newsvendor inventory," Operations Research Letters, vol. 36, no. 5, pp. 569-573, 2008.

[8] X. F. Chen, D. L. Zhu, and W. J. Ying, "Financial and operation decision in budget constrained supply chain," Journal of Management Science in China, vol. 11, no. 3, pp. 70-105, 2008. 
[9] Y. Wen and Q. Ye, "Analysis of the gaming between banks and enterprises under self-liquidating trade finance," China Soft Science, vol. 10, pp. 54-60, 2011.

[10] H. Yu and X. P. Zhen, "Interest rate decision model based on CVAR by considering decision-making behavior of the borrower," Systems Science and Mathematical Sciences, vol. 31, no. 10, pp. 1269-1278, 2011.

[11] H. Yu and Y. W. Wang, "The robust model of interest rate liberalization from supply chain finance perspective," Chinese Journal of Management Science, vol. 24, no. 2, pp. 19-26, 2016.

[12] Y. Y. Tan and Z. Yang, "The optimal strategy of all parties involved in market transaction linkage under the background of interest rate liberalization-from supply chain finance perspective," Management Review, vol. 32, no. 2, pp. 287-298, 2020.

[13] N. Wilson and B. Summers, "Trade credit terms offered by small firms: survey evidence and empirical analysis," Journal of Business Finance \& Accounting, vol. 29, no. 3-4, pp. 317$351,2002$.

[14] J. Tirole, The Theory of Corporate Finance, Princeton University Press, Princeton, NJ, USA, 2006.

[15] R. Fisman and I. Love, "Trade credit, financial intermediary development, and industry growth," The Journal of Finance, vol. 58, no. 1, pp. 353-374, 2003.

[16] S. K. Goyal, "Economic order quantity under conditions of permissible delay in payments," Journal of the Operational Research Society, vol. 36, no. 4, pp. 335-338, 1985.

[17] X. Chen, "A model of trade credit in a capital-constrained distribution channel," International Journal of Production Economics, vol. 159, pp. 347-357, 2015.

[18] H. H. Lee, J. Zhou, and J. Wang, "Trade credit financing under competition and its impact on firm performance in supply chains," Manufacturing \& Service Operations Management, vol. 20, no. 1, pp. 36-52, 2017.

[19] S. A. Yang and J. R. Birge, "Trade credit, risk sharing, and inventory financing portfolios," Management Science, vol. 64, no. 8, pp. 3667-3689, 2017.

[20] H. Peura, S. A. Yang, and G. Lai, "Trade credit in competition: a horizontal benefit," Manufacturing \& Service Operations Management, vol. 19, no. 2, pp. 263-289, 2017.

[21] R. Du, A. Banerjee, and S. L. Kim, "Coordination of two echelon supply chains using wholesale price discount and credit option," International Journal of Production Economics, vol. 143, no. 2, pp. 327-334, 2013.

[22] C. Zhang, Y. X. Wang, and G. H. Han, "Supplier's optimal payment policy under trade credit," Forecasting, vol. 38, no. 4, pp. 90-96, 2019.

[23] H. Gang, X. W. Tang, L. P. Tang, and Y. Y. Guo, "Mechanism and coordination of supply chain under delayed payment," Journal of Systems Management, vol. 28, no. 2, pp. 392-398, 2019.

[24] K. Rana, S. R. Singh, and N. Saxena, "Growing items inventory model for carbon emission under the permissible delay in payment with partially backlogging," Green Finance, vol. 3, no. 2, pp. 153-174, 2021.

[25] B. Pal, A. Mandal, and S. S. Sana, "Two-phase deteriorated supply chain model with variable demand and imperfect production process under two-stage credit financing," RAIRO-Operations Research, vol. 55, no. 2, pp. 457-480, 2021.

[26] A. Nagurney and K. Dhanda, "Marketable pollution permits in oligopolistic markets with transaction costs," Operations Research, vol. 48, no. 3, pp. 425-435, 2000. 